\title{
Syntactic knowledge in Chinese as a third language: Is the first or the second language activated?
}

\author{
Maria Adorjan ${ }^{1}$ \\ ${ }^{1}$ Affiliation not available
}

July 21,2020

\begin{abstract}
This pilot study draws on Vainikka and Young-Scholten's (1994, 1996) Minimal Trees Hypothesis and aims to explore how the grammar of a third language (Chinese) is understood by transferring syntactic knowledge from the learner's first (Hungarian) and/or second language (English). Another aim of the research is to find out whether the selected methodology is suitable for gaining meaningful empirical data that can lend itself to theoretical analysis. First, I will provide a brief introduction to the most important theoretical questions on SLA research, followed by the description of some basic tenets of the Minimal Trees Hypothesis.
\end{abstract}

\section{Hosted file}

Vainikka conf.pdf available at https://authorea.com/users/299731/articles/471314-syntacticknowledge-in-chinese-as-a-third-language-is-the-first-or-the-second-language-activated 